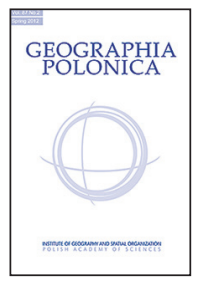 \\ INSTITUTE OF GEOGRAPHY AND SPATIAL ORGANIZATION \\ POLISH ACADEMY OF SCIENCES \\ www.igipz.pan.pl \\ www.geographiapolonica.pl
}

\title{
EMERGING FRONTIERS, CHALLENGES AND CHANGING PROFESSIONAL AVENUES FOR GEOGRAPHERS IN THE CONTEMPORARY WORLD
}

\author{
Ram Babu Singh \\ Vice-President of the International Geographical Union \\ University of Delhi \\ Department of Geography \\ 110007 Delhi: India \\ e-mail: rbsgeo@hotmail.com
}

\begin{abstract}
Geography studies the characteristics of space and place. Geography answers questions such as where things, activities or phenomena are located, why they are located there, how the features and activities interact, and what factors cause this distribution. An ideal geographer exercises both scientific and social analytical skills. Geography has been called a bridge between human and physical sciences. In the beginning, geography focussed on the physical aspects of the earth but modern geography is an all-encompassing discipline that seeks to understand the earth and all of its human and natural complexities as an integrating science. The paper deals with changing professional avenues for geographers, the role of geography towards the future earth and human geosciences together with the role the IGU can play in the Future of World Geography.
\end{abstract}

\section{Key words}

future of geography $\bullet$ global challenges career opportunities $•$ future earth • IGU

\section{Introduction}

Curiosity about various places and people led to the development of geography. Knowledge of geography has existed since the establishment of the earliest human civilisation on Earth. Geography is not just the memorising of place names, it is much more than that and encompasses holistic perspectives. Geography provides a wrapped loaf of bread to those who only need a slice of it. Geography is a synergy of art and science and this unique blend is an outcome of its long journey of evolution. As defined by the IGU (2014) "Geography is the discipline that attempts to explore how environments emerge by natural processes, how societies produce, organise, use, and misuse environments, and how societies themselves are influenced by the environments in which they are located. Thus, 
geography aims to study both the natural and human realms and their interactions, focusing on space, places, and regions, addressing and questioning both short-term and longerterm processes and their resultant patterns." There is a growing discourse concerning the gaining of spatial understanding through scientific explanation. If geography is interested in understanding the world, then it must focus on the basic questions of 'why' and 'how', which are the central enquiries involved in scientific explanation (Harvey 1969). Therefore, geography has been considered as a discipline which studies the Earth as the home of humankind. In this context, it is pertinent to refer to the Indian concept of vasudhaiva kutumbakam (World as one Family).

Geography, being a diverse and multidisciplinary science, deals with the Land-OceanAtmosphere-Human interaction (Singh 2012). Whether in science or social science, it inhabits an upward trend in career prospects in the national and international arena in various disciplines. In a nutshell, geographers identify and analyse the spatial patterns of environmental objects and events that shape our lives. To further highlight the emerging role of the discipline, I would like to draw your attention to the statement given by the Ex UN Secretary General, His Excellency Kofi Annan on the special role played by geographers: "I see four areas in particular where Geographers can make a special contribution to this effort. First is education. Geography class is one of the first places where young people come into contact with the world beyond their immediate community (...). Second is capacity-building in the developing world. The new wave of geographic technology has enormous potential. It can give us earlier warnings of natural disasters and environmental threats and enable us to plan our cities in ways that make them safer to live in (...). Third is the Millennium Ecosystem Assessment, an international collaborative effort to map the health of our planet (...). Fourth, last year we at the United Nations have established a Geographic Information Working Group to improve the way in which many bodies working in our far-flung system use cartographic and geographic information (...). The great adventure of geographic exploration is far from over. But in the future, we must also venture forth on an international landscape - on the mental maps we all carry with us. These maps are built of very personal and local ingredients: our streets, families and livelihoods; our likes and dislikes; our convictions and prejudices. More and more, however, global considerations are pressing in - new products, people and ideas; new opportunities, but also new threats (...). The idea of interdependence is old hat to geographers, but for most people it is a new garment they are only now trying on for size (...). I look forward to working with you on that all-important journey" (Annan 2001: 5).

\section{Geography as an integrating spatial science}

Geography is blessed with the privilege of entering the ambit of both physical and human sciences. Having expertise in the environmental and social aspects, geography can bridge the gap and reject the dichotomy existing between the physical and human sciences (Singh 2012). Interacting areas include environmental geography and disaster management. Geographers study complex nature-human interrelations in a spatio-temporal framework. The region forms the basic unit of analysis for geographers. The study area for the geographer ranges from the universe (abstract space) to the mind (mental space). The discipline of geography uses a variety of techniques for spatio-temporal analysis which include statistics, survey, remote sensing, GIS and GPS (Singh 2009). Geographers can synergize the concepts and philosophies of sub-disciplines within geography as well as between scientists from other disciplines.

Within the realm of human geography Marxist formulations, feminism and postmodernism have served as key interlocutors in the transformation of the discipline and interaction with other fields of social 
science. Gregory (1994) places the corporeality of spatial practices and imaginations and their associated power relations centre stage in geography, from which theoretical formulations should swirl out to deal with issues such as race, gender and class. While exploring the frontiers of geography, Peet (1998) discovered humanistic geography, radical and Marxist geographies, structuralism and realism, post structuralism, postmodernism, and finally, feminist theories, as new arenas in geography. He further concluded that the spatial sciences have declined under the weight of their own internal contradictions. Therefore there is a need to reorient geography as an integrating science in order to resolve inherent contradictions and promote complementarity among its sub-disciplines in order to solve contemporary global geographical problems.

\section{Changing professional avenues for geographers}

Geography in its true sense is an interdisciplinary subject and thus provides ample career opportunities through mapping (AAG 2014). The different branches of physical geography include the sub-themes of geomorphology, fluvial hydrology, oceanography, climatology, climatic variability, and boundary layer interaction, etc. Human geography includes sub-themes of population geography, urban geography, agricultural geography, social geography, cultural geography, etc. A subject is no longer attractive as a discipline if it is unable to provide applied research and adequate job opportunities. The following professions provide career avenues for geographers:

\section{Spatial scientist/analyst}

Objects and phenomena are distributed over space and there exist correlations between distribution of these phenomenon. The spatial-analyst tries to identify, explain, and find meaning in spatial patterns and relationships (e.g. site conditions, how places are similar and different, the influence of a land feature on its neighbours, how places are linked at local, regional, and/or global scales). Spatial Statistics is another related field dealing with the use of quantitative methods to process spatial data for the purpose of making calculations, models, and inferences about space, spatial patterns, and spatial relationships. The professional avenues in the field are:

- Surveyor: Surveying and mapping technicians assist surveyors, cartographers, and photogrammetrists. Together, they collect data and make maps of the earth's surface. Surveyors visit sites to take measurements of land. Mapping technicians use geographic data to prepare maps.

- Spatial information technician: Involved in the scientific, technological and artistic facets of developing, preparing and maintaining maps, charts, plans, three dimensional models and spatial information databases. Traditional methods of map-making have now been superseded by computer based techniques with Geographic Information Systems (GIS) and digital cartography techniques dominating the role.

- Spatial analysis consultant: These enable organisations to use the locational aspect of their information to ultimately improve the effectiveness and efficiency of their operations. They provide a broad range of services covering information management, data collection, geospatial data editing, metadata, spatial data infrastructures, process improvement and geographical analysis.

\section{Manual and digital cartographer}

Maps are core to geography and therefore geographers are more often known by ordinary people as persons who have a special knowledge of maps. Those with a cartography course background enjoy working as cartographers. Government and private agencies and others often search for cartographers to produce maps. Indian geographers are involved in map making as Research Officers at the 
Indian Government agency NATMO (National Atlas and Thematic Mapping Organisation), as Surveying and Mapping Technicians at Survey of India, as Digital Cartographers and as Ocean Navigators.

A cartographer is involved with the scientific, technological and artistic aspects of developing and producing maps. Cartographers present complex information as diagrams, charts and spreadsheets, as well as in the form of conventional maps. Maps and detailed geographical information are needed for a range of purposes, from everyday use by individuals to large-scale business development. Cartographers work in a variety of areas, including publishing, government, surveying and conservation.

\section{Remote sensing and GIS specialist}

The new wave of geographic technology has enormous potential for capacity building in developing countries to map the health of our planet. Geographers use GIS to acquire, manage, display, and analyse spatial data in digital form. Promising tasks for Indian geographers include recording, measuring, and plotting electromagnetic radiation data from earth features using aerial photographs and remote sensing systems from Cartosat, Oceansat, Resourcesat, and RISAT-1 (Radar Imaging Satellite 1). With the development of IRNSS (Indian Regional Navigational Satellite System) and GAGAN (GPS-aided geoaugmented navigation) in India's space programme, geographers try to understand the underlying theories and applications related to acquiring an object (e.g. aerial photography, radar and satellite imaging). The opportunities include:

- Geospatial analyst: The geospatial analyst integrates data relating to various aspects with GIS; serves as a central consultant regarding research related issues; provides instruction, advice, and guidance; and analyses data and geographic networks.

- GIS programme developer: A GIS developer is a software engineer who organises and carries out the activities needed to design and build applications to support GIS data. Using computer programming, they create enhancements to existing GIS software, such as web-based applications. A GIS Developer will often also provide technical support to the application users. In addition to the software responsibilities, they maintain the hardware components of GIS technology like computers, Global Positioning System (GPS) units, and digitizers.

- Photogrammetric specialist: They produce, update and overlay maps to show information boundaries, water locations, or topographic features on various base maps at different scales. They compare topographical features or contour lines with images from aerial photographs, old maps, or other reference materials to verify the accuracy of their identification.

- Geodesist: A geodesist studies the science and shape of our planet as well as its gravitational field. A geodesist measures the size of the Earth on a global scale and also specific regions of land known as fixed points. By doing so, crustal shifts and polar movement can be detected. Measurements can determine the rate of movement and other pertinent information.

- Remote sensing scientist, technologist and analyst: These apply remote sensing principles and methods to analyse data and solve problems in areas such as natural resource management and urban and transport planning. There is also scope to develop new sensor systems, analytical techniques, or new applications for existing systems.

\section{Spatial planner}

Geography is a natural choice within urban or city planning. City planners work on zoning, land use, and new developments, from petrol station renovation to the development of whole new sections of urban areas. They work with individual property owners, developers, and other officials. The edge that 
a geographer has over town planners is their understanding of the integration between different subjects to achieve targets. A proficiency in amalgamating culture, tradition, and societal needs with economics and the physical characteristics of a region is the talent of a geographer alone. It is this cohesive ability that geographers inherit and which makes them better planners. The sub-fields include:

- Urban and regional planner: Urban and regional planners develop plans and programmes for the use of land. They plan to help communities, accommodate population growth, and revitalise physical facilities in towns, cities, counties, and metropolitan areas.

- Geo-intelligence expert: The geospatial intelligence imagery analyst is responsible for analysing aerial imagery developed by photographic and electronic means. They provide Army personnel with critical information about enemy forces, potential battle areas and combat operations support.

\section{Atmosphere, weather and climate change expert}

NOAA and INSAT/GSAT systems have brought a revolution in communication technology. Climatology is a component of geography and studies weather, climate, and atmospheric processes and meteorology (e.g. temperature, precipitation, air quality). Agencies like the IMD, News Media (Weather Channel), and other government bodies occasionally need climatologists. A geographer with experience and an extensive coursework background in meteorology and climatology would definitely be an asset. Therefore geographers have opportunities to serve as a:

- Climate change analyst and climatologist: Climate change analysts evaluate scientific data and carry out research on the climate. They use climate data to create models and to predict probable changes in the earth's climate in the future, as well as their impacts on natural ecosystems and civilisations. Climatologists study changes in the climate as well as the variations in those changes over time and attempt to interpret how the changes affect the earth and its inhabitants.

- Atmospheric and space scientist: They investigate atmospheric phenomena and interpret meteorological data gathered by surface and air stations, satellites, and radar to prepare reports and forecasts for public and other uses. The job includes weather analysts and forecasters whose functions require a detailed knowledge of meteorology.

- Hydro-meteorologist: At the interface of meteorology and hydrology, the hydro meteorologist focuses on fluxes of water and energy between the lower atmosphere and the land surface together with analysing linkages with the El Niño and La Niña phenomenon (Sahu et al. 2013).

\section{Environmentalist, biogeographer and environmental impact assessor}

A plethora of environmental assessment and management establishments exist throughout the world today. A geographer brings excellent skills for project management and the development of reports like environmental impact assessment. It is often a wideopen field with tremendous growth opportunities. Environmental geography gives geographers knowledge about the biological and socio-economic components of geography and hence geographers can also get placed as Geopark Managers, Environmental Impact Assessment Experts, Environmental Scientists, and Environmental Health Specialists. Environmental scientists and specialists use their knowledge of the natural sciences to protect the environment and human health. They may clean up polluted areas, advise policy makers, or work with industry to reduce waste. Environmental scientists and specialists work in offices and laboratories. 


\section{Natural hazards and disaster manager}

With the increasing frequency of disasters in climate change scenarios, geographers have an added advantage in the Disaster Management Authority at both national and international levels. Their knowledge of the spatial distribution of natural hazards is very important for society as it creates awareness among people about hazard zones which helps in mitigating the impact of disasters. There is a need for trained manpower that can assist at the time of the disaster as well as in the planning of schemes and monitoring and management of disasters. With expertise in early warning systems using remote sensing and communication systems, geographers are considered experts in this field. Therefore geographers play a very crucial role as Emergency Response Specialists, Disaster Managers and Consultants, Disaster Risk Assessors, and Hazard Vulnerability Analysts.

\section{Economic geographer, transport planner and multi-level planning specialist}

There are opportunities in local government and regional development authorities and in transportation companies looking for someone wanting to contribute towards informed governance. They should have transportation geography in their background and good computer and analytical skills. Geographers have knowledge about the economy and economic processes (e.g. labour, development, industry, agriculture, transportation, trade, resources, land use, technology change) and can get jobs like Transportation Manager, Market Researcher, Real Estate/SEZ Assessment, Environmental Economist, etc. They also provide network-based spatial analysis, such as routing, travel directions, closest facility, service area, and location-allocation aspects. They use dynamic models to determine realistic network conditions, incorporating information on one-way streets, speed limits, and variable travel speeds based on traffic.

\section{Geomorphologist and Landscape Analyst}

Geomorphology is within the core domain of geographers. It is one of the basic primary sub-branches of geography. A strong foundation of knowledge in geomorphology is essential for any geographical enterprise. In the development of land and water resources, geomorphological knowledge is essential. Geographers study features of the earth and the processes that shape physical landscapes (e.g. soils, hydrology, topography, erosion) and therefore can be employed as Soil and Plant Specialists, Gauge Station Recorders and Water Resources Specialists.

A geophysicist/field seismologist studies the physical aspects of the earth and uses complex equipment to collect data on earthquakes and seismic waves. Their main responsibilities are checking the quality of the seismic data collected and interpreting it in order to create maps. They also examine the physical properties of rocks, as well as gathering and evaluating data from wells that are dug in order to build models for reservoirs.

\section{Hydrologist}

The hydrologist studies the distribution, quality and quantity of water, the hydrological cycle and water resources. The integrative nature required for hydrology comes well under the purview of a geographer. Geomorphological understanding takes inputs from geography and geology. This, combined with a knowledge of oceanography, environment and hydrology, makes a geographer capable of planning water resources.

\section{Population geographer and census atlas maker}

A population geographer can study population size, structures and distribution. They are in great demand in the planning agencies of government in order to prepare plans for sectoral development. Applying geographic information about population, demography, 
and demographic processes (e.g. population density, migration, birth and death rates, fertility rates), geographers are front runners as far as careers in the field are concerned with posts like Map Officers in Census of India, Demographers etc.

\section{Political geographer and geopolitics specialist}

Knowledge of political geography is essential from a national strategic and security point of view. Up until the recent past, military geography has been a subject of study in many universities. Knowledge of maps, boundaries and frontiers is important for the Army and for other strategic imperatives. Geography is very important for understanding political systems and processes (e.g. governments, political activism, non-governmental organizations, nations, states, international relations, nationalism) and therefore geographers can create their own market to get a chance in fields like the Army Education Corps, Policy Consultants and Policy Researchers.

\section{Cultural geographer, and tourism planner and officer}

The Ethnic, Cultural and Tourism sectors also attract geographers. Knowing and applying geographical information about culture and cultural processes (e.g. religion, language, ethnicity, diffusion, perception of landscapes, and cultural significance of place) creates jobs in fields such as Cultural Studies Teachers, Historic/cultural Preservationists, Tourist Consultants and Tourism Officers.

\section{Social geographer and community manager}

Traditionally, geographers have been focused on poverty, crime, regional imbalances and disparities. Social geographers' understanding of the causes of differences and inequalities between places and social groups underlies many newer developments in human geography (RGS 2014).
In the 21st century socio-economic relationships are changing and becoming complex. These complexities need to be simplified. This is only possible when social relations are understood in the wider context of their historical background, economic status, and lifestyle along with the social characteristics in a particular physical setting. The answers to questions like why there is diversity from place to place in society can be answered by knowledge of all these facets. These answers also prompt solutions in our social and community problems our social and community problems. Social geographers and community managers can actively engage communities in building a sense of community ownership and control over the issues which affect their lives, responding to problems and needs through empowerment, and active participation of the individual and community at large. The majority of work is community based, which means that social geographers usually have a specific priority community or social group on which they focus.

\section{Field researcher and explorer}

Historically, geography has been considered as the exploration and discovery of the earth environment. Therefore geographers have been using field and research methods since time immemorial. Geographers use field surveys, interviews, questionnaires, observations, photography, maps, and other techniques to measure geographic information in the field. Geographers have ample opportunities as Researchers, Surveyors, Water Quality Scientists, Field Interviewers, etc. Being expert in both qualitative and quantitative methods, geographers can be engaged in field research related to contemporary socio-economic, demographic, geographical and environmental issues.

\section{Geography teacher and educator}

Geographers have wide knowledge of different aspects of society and environments therefore they have the capability to teach 
various interdisciplinary subjects. Teaching is one of the primary and most respected jobs in every discipline. Geography is one of the few subjects that has been taught at all levels in school. It has been taught from middle school onwards as part of the Social Science discipline and therefore the geographer has opportunities in teaching as a specialist in geography, as a Social Science Teacher in Schools, High School Teacher, Undergraduate Teacher, Postgraduate/University Teacher.

\section{Publishing house and media person}

Various newspapers and magazines are using maps as a tool to present news items and the location of events. The use of accurate maps that can be comprehended by the general public has become a prerequisite. Apart from representing information in terms of statistical data, distribution maps are utilised to represent elements in an effective manner. Hence, a spatial understanding of data and facts is essential.

The publishing sector is a growing sector with more national and international publishing companies entering developing countries. Since geography is taught at school, geographers can be accommodated in editing geography books, writing and proof reading which provide a reasonable salary for school, college and university level books, and also for books for competitive examinations. In this sector one can also earn as a freelance or part timer.

Weather reporting is a traditional job opportunity in this field.

\section{Emerging challenges and the role of geography in the contemporary world future earth specialist}

Geography informs us about the most challenging issues in contemporary science and society. As geographers have the capability to link physical and social phenomena of the Earth's surface, they carry out appropriate, indigenous and solution-orientated research through skill development and innovation in order to promote sustainability and survivability, interlinking environmental change, climate and CDM (Clean Development Mechanism) to fulfill human needs. Geography is able to provide available and timely information relating to disasters for decision/policy-makers by generating the knowledge that will support new and existing global and regional integrated assessments for future needs (Ma et al. 2013). Geography not only provides us with knowledge, but also a method for articulating it, and a unique way of understanding the world around us. Geography provides a unique perspective, bridging the supposed gaps between society and the environment, and between social science, science and the humanities to a future more sustainable.

\section{The geographer as human geoscientist for global environmental governance}

Geographers are involved in effective interdisciplinary collaboration, within the arena of human geosciences, with the physical, natural and social sciences, humanities, economics, psychology and the technological development potential, to find suitable scientific solutions to multi-faceted problems (JpGU 2014). Geographers are continuously making efforts to increase capacity building through the participation of policy-makers, academics, the industrial establishment and other sectors of civil society in science, technology and innovation, especially in developing countries and through the engagement of a new generation of scientists in order to contribute towards effective Global Environmental Governance.

\section{Role of an ideal geographer}

An ideal geographer would promote cross discipline, cultural and regional debate and research initiatives on contemporary issues of the planet earth and global society. Geographers understand the dynamics of nature and the evolution of civilizations and are 
able to promote harmonious relationships between different ideas, behaviour, societies and cultures. In the 21 st century geographers need to have new kinds of integrated scientific research for dealing with the diverse issues of planet earth. As Buttimer (2001a) puts it, "The twenty first century needs a comprehensive and coherent understanding about the sustainability of humanity's lifeways, given the inextricably interlocked processes of global changes in biophysical environments on the one hand and global process based market oriented and capital driven economies on the other. Geographers should find themselves in uniquely strategic positions from which such exploration might be launched." An ideal geographer of future should be a catalyst for transdisciplinary modes of enquiry, ultimately framed in ways which highlight interactions among the human and bio-physical aspects of human ways of life and landscapes (Buttimer 2001b).

\section{The changing role of the International Geographical Union (IGU) for the future of world geography}

On the pattern of the Home of Geography, the Villa Celimontana, IGU should promote the establishment of Homes of Geography at National Level, particularly in developing countries, to serve as a focal point for collecting and distributing information to geographers and promoting interactions between geography with allied disciplines, and national and international research organizations. These may assemble and organize IGU archive materials and serve as a focal and meeting point for geographers from around the world (Home of Geography 2014). Initiatives can start at the continent level and be taken further to the regional and national level. On the pattern of the Festival of Geography in France, IGU can organize an annual IGU global open day for communicating research results to various cross sections of society at various levels. IGU can suggest its national committees regularly to help in revision of the curriculum revision incorporating fundamental and modern techniques and contemporary paradigms such as climate change, food security, water, globalisation, natural disasters, human health and millennium development goals. There is a need to develop an IGU Manual on Curriculum Development.

The IGU Congress should become a platform for dialogue and collaborative research programmes on contemporary thematic areas and critical regions by bridging gaps between geographers, policy makers and community leaders. After the opening ceremony in the IGU congress and regional conferences, a session consisting of representatives from GeoUnions and ICSU (International Council for Science) should be introduced focussing on the cross-disciplinary global challenges faced by the world scientific community. There is a need to reorient the system of Presidential addresses by the IGU President during IGU congresses held every four years. The President should set the agenda and vision to be taken up by world geographers during his address, incorporating contemporary challenges in thematic areas faced by the world geography community. IGU should develop comprehensive strategies for attracting, communicating and focusing on geographers from developing countries and for improving their participation in Congresses to make IGU more participatory.

\section{Concluding remarks}

At present, national imperatives demand a spatio-temporal focus on food, energy, water security, weather, climate, environmental education, health care, skill development, disaster management, space informatics, governance and sustainable development. Synthesising the above information using the concepts and methods of both the natural and social sciences is core to geographical research and its application to attain human security. Geographers use knowledge about environmental and demographic diversity to interpret socio-cultural, economic, environmental, institutional 
and political issues at different spatio-temporal scales by integrating the concepts of the timing of space and the spacing of time. It provides broad, human and place-centred perspectives on the transformation of environments by society and nature at a variety of levels, from the local/regional to the national/ global. Geographers have traditionally been

\section{References}

AAG, 2014. What geographers do. American Association of Geographers, http://www.aag.org/cs/ what_geographers_do [1 February 2014].

AnNAN K., 2001. United Nations Secretary General asks geographers to work on climate change, environmental degradation and sustainable development. International Geographical Union Newsletter, no. 3-4, pp. 1-5.

Buttimer A., 2001a. The president perspective. International Geographical Union Newsletter, no. 1-2, pp. 2-3.

Buttimer A., 2001b. Sustainable landscapes and lifeways: Scale and appropriateness. Cork: Cork University Press.

Gregory D., 1994. Geographical imaginations. Cambridge (Massachusetts): Blackwell.

Harvey D., 1969. Explanation in geography. New York: St. Martin's Press.

Home of Geography, 2014. Paper and video archives. http://www.homeofgeography.org/ [20 January 2014].

IGU, 2014. What is geography? International GeographicalUnion. http://www.igu-online.org/site/ ?page_id=657 [16 January 2014]. involved in a variety of fields and have been absorbed in specialisations in new branches. The opportunities for a geographer are promising as it is integrative science, which is needed at this time. The realisation of these prospects and making the universities and geographical unions more market oriented could be the panacea of world development.

JpGU, 2014. Overview. Japan Geoscience Union, http://www.jpgu.org/index-e/sciencesection/ overview.html [25 January 2014].

Ma M., Haapanen T., Singh R.B., Hietala R., 2013. Integrating ecological restoration into CDM forestry projects. Environmental Science and Policy, vol. 38, pp. 143-153.

PEET R., 1998. Modern geographical thought. Oxford: Blackwell.

RGS, 2014. What is geography? Royal Geographical Society. http://www.rgs.org/GeographyToday/What+is+geography.htm [27 January 2014].

Sahu N., Behera S.K., Ratnam J.V., Da Silva R.V., Parhi P., Duan W., Takara K., Singh R.B., Yamagata T., 2013. El Niño Modoki connection to extremely-low streamflow of the Paranaiba River in Brazil. Climate Dynamics, vol. 42, no. 5-6, pp. 1509-1516.

SINGH R.B., 2009. Remote sensing and geographical information system [in:] L.S. Bhat, Geography in India: Selected themes. New Delhi: Pearson Education India, pp. 203-257.

SINGH R.B., 2012. Progress in Indian geography: A country report 2008-2012. New Delhi: Indian National Science Academy. 